\title{
Context effects: Classroom tests and context independence
}

\author{
WILLIAM H. SAUFLEY, JR., SANDRA R. OTAKA, and JOSEPH L. BAVARESCO \\ University of California, Berkeley, California
}

\begin{abstract}
Contextual dependence has been hypothesized to influence classroom test performance such that taking a test away from the lecture room should lead to lower test scores (Abernethy, 1940). We studied the performances of students who took typical college tests in rooms different from the lecture rooms and made comparisons to classmates who remained in the lecture rooms. No statistically reliable effects were found in 21 such comparisons in seven courses. Although contextual dependence has been produced under laboratory control, college classes induce students to decontextualize information. The theoretical utility of contextual associations is based on sim. pler, more tightly controlled conditions, and generalization to representative situations is an em. pirical matter.
\end{abstract}

When exposed to old and familiar environments, we generally are impressed by recollections of events long forgotten. Occurrences like these have not gone unnoticed in laboratory research, for environmental or contextual stimuli have played an important role in theoretical accounts of memory function (see Anderson, 1980; Carr, 1925; Estes, 1959; McGeoch, 1942; Tulving \& Thompson, 1973). In an effort to understand the effect of contextual cues in nonlaboratory settings, we sought to find out whether a change in environmental context, specifically a change in classroom for a midterm examination, would influence students' scores.

Indeed, McGeoch (1942) and others (e.g., Crowder, 1976; Smith, Glenberg, \& Bjork, 1978) have referred to Abernethy's (1940) work as demonstrating diminished recall when students were tested in a different classroom or with a different proctor. Influence of a changed classroom upon test performance is reasonable. To the extent that an examination is thought of as requiring recall of material learned in and associated with the lecture-room context, removal of that critical context could lead to lower recall. Several laboratory experiments have reported context dependency in recall. We were impressed by the apparent potency of contextual associations and the potential consequences for students who must take examinations in different classrooms in order to relieve crowding. However, we were disappointed by the absence of statistical comparisons in Abernethy's much earlier work. Accordingly, the object of this paper is to study whether,

This research was supported in part by a generous gift from Steve Wozniak. We would like to thank Dawn Adams, Curt Samuels, Tim White, and Charles Woodson for their generous cooperation. Sandra R. Otaka is now at the School of Law, University of California. Los Angeles. Request for reprints should be addressed to W. H. Saufley, Jr., Department of Psychology, University of California, Berkeley, CA 94720 . in typical course circumstances, a changed classroom (context) for an examination would lower students' scores.

The context with which we are concerned is the complex of environmental stimuli in which a class takes place, rather than the discrete events during learning which are part of stimulus encoding (Tulving \& Thompson, 1973). Included in the general context are the walls, seating capacity and arrangement, room location, lighting, noises, odors, other people in the room, and even the student's customary seat. In order for these stimuli to be effective for recall, any learning that takes place within the context must be connected reliably with the characteristics of the room that distinguish it from other environments. During students' attempts to recall information learned in the environment, the physical presence of relevant contextual stimuli should increase the probability that the previously learned information will be remembered. Similarly, the absence of those cues and the presence of others should decrease the probability that the information will be remembered.

In order to briefly review the effect of contextual cues upon recall, it is helpful to distinguish between two situations: the controlled conditions of the laboratory and the relatively uncontrolled conditions of nonlaboratory or natural conditions.

Two designs generally have been used to uncover contextual effects in laboratory research: an interference (RI) design and simple retention (training followed by a test). With RI designs, context is changed during interpolated learning. Studies using simple retention vary the context between training and test. In the laboratory, changes in contextual stimuli have a systematic influence upon RI. Bilodeau and Schlosberg (1951) showed that, by changing the context (room) in which interpolated learning took place, RI was reduced (see also Greenspoon \& Ranyard, 1957). Although there is some question about whether the context change itself or disruption in the experimental procedure is responsible for the reduction in RI (Strand, 1970), there are still evidential reasons for accepting that 
alterations in contextual cues can produce changes in RI (Godden \& Baddely, 1975; Smith et al., 1978).

Laboratory tests of simple recall, in which recall follows learning in either the same or a different context, also have produced evidence of contextual dependence. $A$ reduction in recall has been found in children ranging from Grades 2 to 12 when learning and testing were carried out in different room environments (Jensen, Harris, \& Anderson, 1971). Moreover, with a variety of experimental variations of contextual conditions, Smith (1979; Smith et al., 1978) has provided clear evidence that environmental cues are effective means for manipulating recall performance. Eich (1985) was able to show context dependence only when subjects were required to form visual-image associations between a to-be-remembered word and a particular feature of the first room.

In a nonlaboratory setting, Godden and Baddely (1975) tested scuba divers in two conditions: on land or approximately $20 \mathrm{ft}$ underwater. Divers tested in a different environment from their learning environment showed significantly lower recall scores. When learning and recall took place in the same environment, mere disruption did not produce an effect upon recall. Even though such dramatic change in context is not encountered normally, it does appear that, under special conditions, a change in context will produce lower recall even in a simple test of recall.

The classroom provides a more typical nonlaboratory situation for observing the occurrence or nonoccurrence of contextual dependency. Abernethy (1940) factorially compared changed classroom and proctor on examination scores. In the two studies presented in her paper, the largest numerical difference was found when both classroom and proctor were changed during the test. However, her paper was published before statistical tests of reliability became a routine part of reporting research. Although Abernethy reported means and standard deviations, the design is a repeated measures factorial, and so these data cannot be subjected now to statistical analysis. The numerical differences in test scores evidently led to the conclusion that context did have an effect on scores, even though the results were not supported by tests of statistical reliability. Still, using standards of the day, Abernethy cautioned that there was "not a high degree of statistical reliability in the differences obtained" ( $p$. 300 ). One other early attempt of a similar nature did not report an effect (Farnsworth, 1934).

Metzger, Boschee, Haugen, and Schnobrich (1979) tested two separate sections of physical geography laboratory students in a room "essentially the same as the regular classroom" (p. 441) and showed either a doubling or a $30 \%$ increase in percent errors on a weekly quiz. The effect reported was quite large, but it was produced when the environmental contexts were essentially identical. Thus, their results present some difficulty of interpretation in the light of laboratory research in which environmental context has been noticeably varied.
Guided by theory, contextual dependence has been obtained under some laboratory conditions. However, we have very little experience for using theory to make predictions in the cognitively and socially rich conditions of the natural environment of the college student, and so we turn to experimental evidence. The hypothesis advanced in Abernethy's study led us to obtain fresh evidence to determine whether a change in classroom for an examination would indeed result in lower performance by students. The question we address is whether, under routine conditions of classroom activity, a change in examination environment (different than lecture room) alters contextual associations sufficiently to reduce students' test performances.

\section{METHOD}

Our intention was to keep as close as possible to classroom routine and to collect data from courses in which additional classroom space was used during tests. We collected data over a period of 3 years from seven undergraduate courses on the Berkeley campus of the University of California. In every case, the number of students tested outside of the lecture room depended upon the availability of additional classroom space at the hour of the test and, therefore, varied among the experiments.

We should emphasize that our intention was to capture standard class procedures in these natural experiments, including various ways instructors assign students to the different classrooms. Although the methods used for assignment may not meet customary standards of laboratory practice, they are nonetheless familar to us.

Each course used an unsystematic selection procedure which the instructor preferred and considered unbiased. Students were told routinely that additional room space was being used to relieve crowding in the lecture room and permit more thorough monitoring of the exam. This is a usual procedure in many courses, and there was no indication that the students considered the move as being out of the ordinary. The choice of alternate room space was governed by balancing practical considerations that included the number of teaching assistants who could assist with proctoring, the seating capacities of the rooms, and the physical locations of the rooms. The tests were proctored by the professor and the teaching assistants for the particular course. In those experiments for which several rooms were used, teaching assistants proctored the alternate classrooms

No modifications of the alternate rooms were attempted. None of the instructors wanted to introduce any condition that possibly could lead to lower performance by their students during the tests.

\section{Experiment 1}

Students in an advanced psychology course took two midterm exams. Both were 2 -h exams consisting of a short multiple-choice section and short-essay questions.

\section{Midterm 1}

Subjects. A total of 253 students participated. Of those students, 237 were tested in the same context condition (lecture room). Two students from each page of the class list $(n=16)$ were selected by random drawing to be tested in the changed context condition (nonlecture room)

Procedure and test conditions. On the day of the test, the students went directly to their assigned rooms. The same context group was tested in a large auditorium, seating about 300 in amphitheater arrangement. The room had permanent desks, no windows, and a long lecture or demonstration table across the front of the room. 
The changed context students were tested in a different building in a small classroom with no windows and a seating capacity of 20. Instead of desks, there were large gray metal tables on which students could write. All students took identical tests.

\section{Midterm 2}

Subjects. A total of 250 students took the second test: 198 students were tested in the same context condition and 52 students were tested in the changed context condition.

Procedure and test conditions. Again, students were assigned to the alternate classrooms by a random drawing of three or four names from each page of the class list. The students went directly to their assigned rooms on the day of the test. The same context room was the same as in the first midterm.

Two rooms in different buildings were used for the changed context condition. Thirty students took the exam in a chemistry demonstration room containing 60 movable desks. Seating was placed on two stepped risers toward the rear of the room, and one wall contained several windows. The other changed context room did not have windows and seated 25 in movable desks arranged on a level floor.

\section{Experiment 2}

Students in a computer science course took two midterms. The first exam tested conceptual knowledge with short essays, and the second exam consisted of problems in computer programming.

\section{Midterm 1}

Subjects. A total of 255 computer science students were tested: 165 students took the test in the same context condition and 90 students were tested in the changed context condition.

Procedure and test conditions. On the test day, students were handed their exam papers as they arrived at the regular lecture hall. Ninety of the exams had been marked and interspersed among the stack of exam papers. Students receiving a marked exam went directly to the different classroom.

The same context group was tested in a large lecture hall with a seating capacity of about 380 . The room had permanent desks and no windows. The changed context room was a smaller lecture hall in the same building with a seating capacity of about 180 and four large windows. The seating was raised in amphitheater style in both lecture halls.

There were two equivalent forms of the exam distributed equally in the two contexts.

\section{Midterm 2}

Subjects. A total of 175 students took the second midterm: 124 students took the exam in the same context condition, and 51 students in the changed context condition.

Procedure and test conditions. The method of assigning students to the two rooms was the same as in the first midterm. The two rooms were also the same. Due to the way in which students were assigned to the two rooms, it is probable that for some students the changed context was the same room in which they had taken the first midterm.

Again, there were two equivalent forms of the test equally distributed in the two context conditions.

\section{Experiment 3}

Students in an introductory psychology course took one midterm composed of multiple-choice, true-false, and shon-answer questions.

\section{Midterm 1}

Subjects. A total of 272 students participated: 252 of those students were tested in the same context condition and 20 students were tested in the changed context condition.

Procedure and test conditions. The 20 students in the changed context conditions were unsystematically selected from the class list and assigned to the alternate, smaller classroom when the class had assembled for the exam.

The same context room was an auditorium with a seating capacity of about 250 permanent desks and no windows. There was an elevated stage across the front of the room. Because the number of students present for the test exceeded the seating capacity of the room, some students took the exam while sitting on the stage and steps in the room. The changed context room was a small classroom in the same building. This room had about 50 fixed seats and windows along one wall.

\section{Experiment 4}

Students in a physical anthropology course took two midterm exams composed of multiple-choice, fill-in-the-blank, true-false, and short-essay guestions.

\section{Midterm 1}

Subjects. A total of 822 students enrolled in the course took the first midterm: 732 were tested in the same context condition and 90 were tested in the changed context condition.

Procedure and test conditions. Students who took the test in the alternate classroom were chosen according to the first letters of their last names. Two letters of the alphabet were chosen which gave the appropriate number of students, 90 , suitable for the room. In order to reduce confusion in the class, the same students were assigned to the alternate classroom for both tests. On the day of the test, the students went directly to their appointed rooms.

The lecture room for the same context condition was a large auditorium with about 800 fixed seats. There was a raised stage across the front of the room and there were no windows. The changed context room was a small auditorium for screening movies located in the film archive building about one block from the main campus area. It contained about 200 fixed seats and did not have windows.

\section{Midterm 2}

Subjects. Seven hundred ninety-three students took the second midterm. Seven hundred ten took the test in the same context condition and 83 took the test in the changed context condition. The 83 students were from the same group of students who were selected earlier to take both exams in the alternate room. Consequently, the changed context room was familiar to them.

Procedure and test conditions. Again, the students went directly to their assigned rooms on the day of the test. The same rooms used in the first midterm were used again.

\section{Experiment 5}

Students in another year's offering of physical anthropology, by the same instructor as in Experiment 4, took two midterm exams. Only the second midterm is reported here. Room scheduling difficulties resulted in all of the students taking the first midterm outside the lecture hall. The room was a large auditorium on campus with two levels of seating, main floor and a balcony.

There were two rooms used for the changed context condition in the second midterm. Because each room was located in a different area of the campus and was quite distinct from the other as well as from the lecture hall, the two changed context rooms are reported separately.

The text consisted of multiple-choice, fill-in, true-false, and shoressay questions

\section{Midterm 2}

Subjects. Six hundred fifty-nine students took the second midterm: 423 were tested in the same context condition and a total of 236 were tested in two changed context rooms, 92 in the first alternate room and 144 in the second.

Procedure and test conditions. Students' names were selected sequentially from the class roll and assigned to one of the exam rooms. Beginning with the first "A," names were selected until 
the capacity of the first room, Changed Context 1, was reached. Beginning with the next name, 144 students were selected for the second alternate room, Changed Context 2 . The remaining students took the exam in the lecture hall.

The lecture hall was the same as in Experiment 4, a large auditorium seating about 800 . Changed Context 1 was the same room in the film archive building used in Experiment 4. It was located about one block south of the central campus. The Changed Context 2 room was another theater-style room located in a building across a public street to the east of the central campus. The room had a cathedral-style ceiling with wood lighting fixtures hanging from beams and no exterior windows. The walls of the room were paneled in dark wood, and a curtain was drawn across the raised stage located at one end of the room. The floor of the room did not have permanent seating and could be arranged to suit a variety of functions. For the exam, students sat at round banquet tables arranged about the room to allow ease of movement. Due to the specialized nature of these particular rooms, it is highly probable that the students had not been in these rooms before.

\section{Experiment 6 and 7, General Comments}

Two successive years' offerings of an introductory biology course, with different instructors, constitute Experiments 6 and 7. We describe some common features of these two courses together because of the way students were assigned to midterm locations and, consequently, the opportunity it gave us to contrast the changed context with the same context conditions. The exams contained multiple-choice, true-false, fill-in-the-blank, and short-essay questions.

The tradition in this course was to use the laboratory sections, with a maximum of 30 students in each, as the means of assigning exam rooms. Enrollment in lab sections was dependent upon a number of factors including student choice at the beginning of the course, scheduling changes, and unsystematic assignment to make each section approximately equal in size. Each lab section was the responsibility of a teaching assistant who had the primary obligation to maintain students' pace through the course. There was no reason to suppose that enrollment in any lab section was determined by student ability.

The number assigned to any room for the midterm was dictated by the joint need to have all students in a given lab section in the same room and to reduce crowding. A variety of alternate rooms were made available. We grouped the alternate rooms into categories in order to make comparisons to the same context scores. The two experiments have different groupings and are described separately.

\section{Experiment 6}

Subjects. Four hundred ninety-six students took Midterm 1 and 485 students took Midterm 2.'

Procedure and test conditions. The same context condition was a large lecture hall with no windows, seating in ampitheater style, and a long demonstration table across the front of the room. Students were assigned to various alternate sites for the midterm exams by lab section as just described.

We categorized the various alternate rooms into three groups: Changed Context $1-$ a variety of different rooms, but a student took both midterms in the same location. Changed Context 2 -different rooms and a student took each midterm in a different location; and Changed Context 3-students took both midterms in their customary lab rooms.

\section{Experiment 7}

Subjects. Seven hundred eighty-seven students took Midterm 1 and 768 took Midterm 2.

Procedure and test conditions. The same context room was the same lecture room as in Experiment 6 . A student in the changed context condition took both exams in the same alternate location. We categorized the various alternate rooms into three groups: Changed Context $1-$ a variety of different rooms which we judged to be relatively dissimilar to the lecture room; Changed Context 2-a variety of different rooms which we judged to be relatively similar to the lecture room; and Changed Context 3-students took the midterms in their customary lab rooms.

\section{RESULTS}

The test scores from each of the various classes were used to measure the effect of context change. The total points available varied among the tests, but each instructor considered his/her tests to be adequate for measuring students' competency with the course material. Because each of the various tests had different total points available, the mean scores varied considerably from test to test. Furthermore, due to constraints of alternate classroom availability, the number of students tested in a changed context condition was usually smaller than the number of students tested in the same context condition.

We used a $p<.05$ to measure statistical reliability in all experiments. The mean test scores are presented in Table 1 along with the outcomes of the statistical tests of significance.

All comparisons were nonsignificant. In seven independent courses, 21 comparisons of a change in classroom environment for an exam did not produce a change in test performance. ${ }^{2}$ Furthermore, the direction of mean differences was not consistent, as expected from a finding of no statistically reliable differences.

We were unable to identify questions as uniquely derived from the lecture room context, or outside of the lecture room, which might reveal context dependence. The courses sampled emphasized integrated material on midterm exams. Although a question or two could be identified as drawing from a narrowly prescribed source, no instructor was willing to ascribe the reliability to one item out of many which would make analysis fruitful.

\section{DISCUSSION}

Absence of evidence for contextual dependence in the experiments reported here leads to the conclusion that there are apparent limits to the influence of contextual associations. Previously, Farnsworth (1934) reported that classroom changes did not lower test scores, and Abernethy's (1940) results were equivocal. The result of Metzger et al. (1979) was obtained, evidently, in the absence of a noticeable difference in environmental context, and we do not have a ready interpretation in terms of variation in environmental context. In the studies examined here, only when tests were given either underwater or on land (Godden \& Baddely, 1975) has a nonlaboratory study produced a significant context effect. Laboratory studies, however, have produced context dependence in recall. Faced with this evidence, the question is not whether context can influence recall, because it can. Rather, the question is whether context must have an effect in more variable and representative settings. Of course, unlike laboratory tests, college exams are not exclusively tests of rote memory. College classes do have other charac- 
Table 1

Mean Test Scores

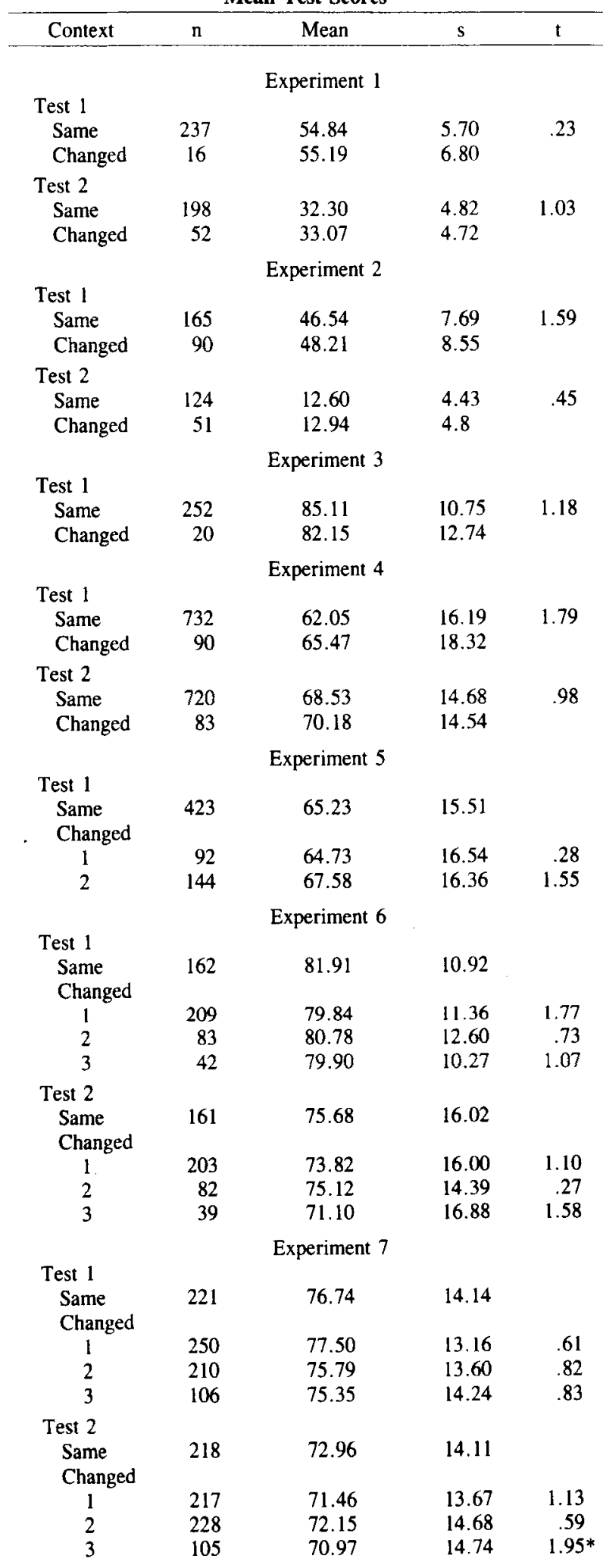

*Because the obtained value is close to the critical value of 1.96 , all calculations were carried out to four places. teristics that could account for the lack of influence of contextual associations and even make the classroom an inappropriate environment for testing contextual dependence. Among these are the way in which variables are expressed, educational goals in literate societies, and the nature of representative situations.

First, we will consider the ways in which potentially effective variables occurred in the classroom situations. It could be that potentially effective variables are not sharply defined in classroom conditions and, thus, are impotent. For example, the range of contextual variation, that is, the differences in the classrooms, could be inadequate. Smith (1979) already has shown that context dependence diminished when the uniqueness of the environmental conditions was reduced by exposing the students to a variety of testing rooms. To the extent that the usefulness of contextual associations depends on the distinctiveness of the environmental conditions, a blurring of the distinctiveness through experiences with a variety of classrooms should reduce the role of context. An inspection of the classrooms used in the present experiments left no doubt that the changed contexts were noticeably different from the lecture room in dimensions, appointments, lighting, and sometimes location on campus. Informal comments by some of the students who took the tests in the different rooms indicated that the changes were very noticeable and in some instances initially unsettling, but after beginning the tests, students tended to disregard the room. However, the overall distinctiveness of any of the rooms might be decreased by the students' experience with college classrooms. In the normal course of taking classes, students are exposed to a variety of classrooms available on a college campus. When compared to this background of different rooms, the alterations introduced here could have been too small to produce context dependence. An exception is Experiment 5: The location and unique physical characteristics of both alternate rooms rendered them particularly distinctive.

Also, it should be recognized that removing some students from the lecture room changes aspects of the lecture room context. For example, fewer students means more empty seats in the lecture room; friends and familiar neighbors in the lecture room are missing; the temperature of the lecture room might change noticeably in certain seasons of the year; and so on. Very simply, manipulation of the experimental variable necessarily produces contextual changes in the putatively same context. This design feature is part of any classroom study and, thus, compromises the control condition.

Despite not finding an effect of classroom change, there is no way from this study to distinguish between the possibility that contextual associations are not formed or, if formed, are simply useless. Test questions and problems in college classes are intended to serve as sufficient retrieval cues for the test answers. As with state-dependent retrieval (Eich, 1980), context dependence is more likely 
when other, more specific retrieval cues are absent. Adequate retrieval cues could be present in the test questions themselves, thus producing a relative weakening of contextual associations.

The second, and perhaps most important, feature is a fundamental characteristic of formal education in literate societies which mitigates contextual dependence in the classroom. We cultivate a variety of habits in formal education: taking notes and using textbooks and other reference sources so that substantial study time occurs outside of the lecture room; learning material so that it can be produced in a variety of situations in the future; extracting meaning and thematic information, and applying the knowledge to other, yet unforeseen circumstances. Formal education uses many forms of source material and encourages thoughtful study and reflection beyond the lecture room, laboratory, discussion section, and textbooks. The consequence is to remove information from a particular context, effectively decontextualizing the material learned.

The third circumstance is a consequence of the very nature of representative situations. Laboratory evidence leads us to conclude that contextual dependence can occur when conditions render contextual associations advantageous for retrieval of information from memory. However, extension of laboratory effects to natural settings introduces complex factors, not envisioned by theory, which can negate effects clearly expressed under experimental control. Theory makes predictions about the action of variables in simple situations. In complex or more representative situations, there are many other variables which singly or in concert make it unlikely that contextual associations would influence test performances sufficiently to be noticed. Rather than anathematize theory, we should acknowledge the hazard of attempting to understand natural events by extrapolating one factor at a time. In complex situations, it is experimental evidence, not theory, that is our guide.

We do not doubt that contextual information can be stored along with other learned information. Nor do we doubt the role that context can play in such familiar experiences as involuntary memories (see, e.g., Salaman, 1982), in which the unbidden occurrence of a memory is attributed to a chance encounter with an associated contextual stimulus. The question is whether contextual cues must be effective when contextual conditions vary. There is no evidence in these natural experiments that a change in classroom context affects test performance.

There is, perhaps, a lesson about the nature of the human subject that can be drawn from a comparison of data from classroom and various laboratory situations. The human mind is remarkably adept at functioning in ways which serve the demands of the task at hand (Jenkins, 1981). The requirements of the college classroom are different from requirements of the laboratory and, correspondingly, the way in which students deploy memory is also different. We are left, then, with an appealing arena for extending theory, but the typical college class environment presents a very low probability set of retrieval cues for test performance and appears to be an irrelevant site to test contextual dependence.

In the natural ecology of the undergraduate classroom, contextual associations are rarely an advantage and would certainly be a disadvantage to the student whose knowledge would be associated to the study hall, dormitory, or even the delicate fragrance once worn by the student in the next seat.

\section{REFERENCES}

ABERntihy, E. M. (1940). The effect of changed environmental conditions upon the results of college examinations. Journal of Psychol. ogy, 10, 293-301

Anderson, J, R. (1980). Cognitite psychology and its implications. San Francisco: Freeman.

Bilodfau, I. MCD. \& SCH losBerg, H. (1951). Similarity in stimulating conditions as a variable in retroactive inhibition. Journal of Experimental Prichology, 41, 199-204

CARr, H. A. (1925). Psychology, a study of mental acrivity. New York Longmans, Green

Crowder, R. C. (1976). Principles of learning and memon: Hillsdale, $\mathrm{NJ}$ : Erlbaum

EICH, J. E. (1980). The cue-dependent nature of state-dependent retrieval Memory \& Cognition, 8, 157-173.

EıcH, E. (1985). Context, memory, and integrated item/context imagery. Journal of Experimental Psychology: Learning, Memory, \& Cogni tion, 11, 764-770

Estes, W. K. (1959). The statistical approach to learning theory. In S. Koch (Ed.), Psychology: A study of a science (Vol. 2). New York: McGraw-Hill.

FarNsworTH, P. R. (1934). Examinations in familiar and unfamiliar surroundings. Journal of Social Psychology, 5, 128-129.

GodDEN, D. R. \& BADDELy, A. D. (1975). Context-dependent memory in two natural environments: On land and underwater. British Jour nal of Psychology, 66, 325-332.

Greenspoon, J.. \& Ranyard, R. (1957). Stimulus conditions and retroactive inhibition. Journal of Experimental Psychology, 53, 55-59.

Jenkins, J. J. (1981). Can we have a fruitful cognitive psychology? In J. H. Flowers (Ed.), Nebraska Symposium of Motivation 1980, Vol. 28, Cognitive Processes (pp. 211-238). Lincoln: University of Nebraska Press.

Jensen, L. C., Harris, K. \& Anderson, D. C. (1971). Retention following a change in ambient contextual stimuli for six age groups. De velopmental Psychology, 4, 394-399.

Metzger, R. L., Boschee, P. F., Haugen, T., \& Schnobrich, B. L. (1979). The classroom as learning context: Changing rooms affects performance. Journal of Educational Psychology, 71, 440-442.

McGeoch, J. A. (1942). The psychology of human leaming: An introduction. New York: Longmans, Green.

Salaman, E. (1982). A collection of moments: A study of involuntary memories. In U. Neisser (Ed.), Memory Observed (pp. 49-63). San Francisco: Freeman.

Smith. S. M. (1979). Remembering in and out of context. Journal of Experimental Psychology: Human Learning \& Memory, 5, 460-471.

Smith, S. M., Gl.f.nberG, A., \& Bjork, R. A. (1978). Environmental context and human memory. Memory \& Cognition, 6, 342-353.

Strand, B. Z. (1970). Change of context and retroactive inhibition. Journal of Verbal Learning \& Verbal Behavior, 9, 202-206.

Tulvinc;, E., \& Thompson, D. M. (1973). Encoding specificity and retrieval processes in episodic memory. Psychological Review, 80 , 352-373. 


\section{NOTES}

1. Some of the class was not included in our analysis because room assignments changed from one midterm to the next in ways that did not fit our categories. Nonetheless, we compared the omitted sections with the appropriate same context score and did not find any significant differences. These data are omitted simply to make it easier for us to describe the results.
2. An identical result of no effect was found in a natural experiment similar to these but carried out prior to and independently of ours. The means for same and changed context were $58.5(n=125)$ and 59.1 $(\mathrm{n}=97)$, respectively, with $\mathrm{t}<1$. We thank Seth Roberts for furnishing us with this data from his introductory psychology course.

(Manuscript received August 13, 1984; revision accepted for publication August 15, 1985.) 